\title{
Mepolizumab effectiveness in patients with severe eosinophilic asthma and co- presence of bronchiectasis: a real-world retrospective pilot study
}

\section{Claudia Crimi ${ }^{\mathrm{a}}$ MD, PhD}

${ }^{a}$ Respiratory Medicine Unit, "Policlinico-Vittorio Emanuele San Marco" University Hospital, Via S. Sofia, 78, 95123, Catania, Italy, dott.claudiacrimi@gmail.com

Raffaele Campisi ${ }^{\mathrm{a}} \mathrm{MD}, \mathrm{PhD}$,

${ }^{a}$ Respiratory Medicine Unit, "Policlinico-Vittorio Emanuele San Marco" University Hospital, Via S. Sofia, 78, 95123, Catania, Italy, raffaelemd@hotmail.it

\section{Santi Nolasco ${ }^{\mathrm{b}}$ MD}

${ }^{b}$ Department of Clinical and Experimental Medicine, Section of Respiratory Medicine, University of Catania, Via Santa Sofia 78, 95123, Catania, Italy, nolascos@hotmail.it

\section{Giulia Cacopardo ${ }^{\mathrm{b}}$ MD}

${ }^{b}$ Department of Clinical and Experimental Medicine, Section of Respiratory Medicine, University of Catania, Via Santa Sofia 78, 95123, Catania, Italy,

\section{giuliacacopardo@gmail.com}

\section{Rossella Intravaia ${ }^{\mathrm{b}}$ MD}

aRespiratory Medicine Unit, "Policlinico-Vittorio Emanuele San Marco" University Hospital, Via Santa Sofia 78, 95123, Catania, Italy, rossellaintravaia@gmail.com

\section{Morena Porto ${ }^{\mathrm{b}}$ MD}

bDepartment of Clinical and Experimental Medicine, Section of Respiratory Medicine, University of Catania, Via Santa Sofia 78, 95123, Catania, Italy, morenaporto@virgilio.it

\section{Pietro Impellizzeri ${ }^{\mathrm{b}}$ MD}

${ }^{b}$ Department of Clinical and Experimental Medicine, Section of Respiratory Medicine, University of Catania, Via Santa Sofia 78, 95123, Catania, Italy,

\section{pietroimpellizzeri2018@gmail.com}

\section{Corrado Pelaia ${ }^{\mathrm{C}}$ MD}

'Department of Medical and Surgical Sciences, University "Magna Graecia”, Catanzaro, Italy, pelaia.corrado@gmail.com

\section{Nunzio Crimi ${ }^{\mathrm{a}, \mathrm{b}}$ MD}

${ }^{a}$ Respiratory Medicine Unit, "Policlinico-Vittorio Emanuele San Marco" University Hospital, Via S. Sofia, 78, 95123, Catania, Italy

${ }^{b}$ Department of Clinical and Experimental Medicine, University of Catania, Via Santa Sofia 78, 95123, Catania, Italy, crimi@unict.it 


\title{
Corresponding author:
}

\author{
Claudia Crimi MD, PhD \\ Respiratory Medicine Unit, \\ "Policlinico-Vittorio Emanuele San \\ Marco" University Hospital, \\ Via S. Sofia, 78 \\ 95123, Catania \\ Italy \\ Phone/FAX 0953781423 \\ dott.claudiacrimi@gmail.com
}

Funding: This research did not receive any specific grant from funding agencies in the public, commercial, or not-for-profit sectors.

\begin{abstract}
Abbreviations: Severe eosinophilic asthma (SEA); Bronchiectasis (BE); Bronchiectasis severity index (BSI); Body mass index (BMI); Chronic Rhinosinusitis with Nasal Polyps (CRSwNP); Gastroesophageal reflux disease (GERD); Inhaled Corticosteroids - LongActing Beta-Agonist (ICS-LABA); Long-Acting Muscarinic Antagonist (LAMA); Chronic Mucus Hypersecretion (CMH); oral corticosteroids (OCS); Asthma Control Test (ACT); Forced expiratory volume in the 1st second (FEV1); Immunoglobulin-E (IgE); Fractional Exhaled Nitric Oxide (FeNO); European Respiratory Society (ERS); American Thoracic Society (ATS); Global Initiative for Asthma (GINA).
\end{abstract}

Keywords: mepolizumab, severe eosinophilic asthma, bronchiectasis, anti-IL-5, eosinophils, neutrophils, mucus secretion 


\section{Highlights}

- Mepolizumab is effective in the treatment of severe eosinophilic asthma (SEA) in clinical trials and real-life studies.

- Bronchiectasis is a frequent comorbidity in patients with severe eosinophilic asthma.

- Mepolizumab proved to be effective in improving asthma symptoms control, mucus hypersecretion, lung function, and reducing sputum and blood eosinophils, corticosteroids dependency and annual exacerbations both in severe eosinophilic asthma patients with or without co-presence of bronchiectasis.

- Mepolizumab showed to be effective in patients with asthma and co-presence of bronchiectasis, regardless of BE severity.

- Assessing the co-presence and severity of bronchiectasis may help clinicians select the right biologic for a prompt treatment-specific effect. 


\section{Abstract}

Background: The association of bronchiectasis (BE) in patients with severe eosinophilic asthma (SEA) is quite frequent. Mepolizumab is a well-recognized treatment for SEA; we aim to evaluate its effectiveness in SEA patients with and without BE in real-life.

Methods: We performed a single-center retrospective pilot study, including patients with SEA treated with mepolizumab for one year. Asthma control test (ACT), lung function, annual exacerbations rate, oral corticosteroid dosage, FeNO, chronic mucous secretions, blood and sputum eosinophils were recorded at baseline and after 6 and 12 months.

Results: we included 32 patients (mean age: $52.3 \pm 10,59 \%$ female). $50 \%$ showed copresence of bronchiectasis, $(\mathrm{SEA}+\mathrm{BE})$. Significant improvements were found in $\mathrm{ACT}$ $[(13.8 \pm 4.6$ to $20.7 \pm 4.1, p=0.0009)$ and $(13 \pm 4.8$ to $20.7 \pm 4.6, p=0.0003)]$, annual exacerbations rate [from $7(4-12)$ to $0(0.00-0.75)$ and from $8(4-12)$ to $0(0-1), p<0.0001$, and blood eosinophils count $[748$ cells $/ \mu \mathrm{L}(400-1250)$ vs. 84 cells $/ \mu \mathrm{L}$ (52.5-100), and from 691 cells $/ \mu \mathrm{L}(405-798)$ vs. 60 cells $/ \mu \mathrm{L}(41-105), \mathrm{p}<0.0001]$ in SEA and SEA+BE group respectively, already after 6 months of treatment. A reduction in daily oral corticosteroids intake at 12 months was shown [from $15 \mathrm{mg}(0-25)$ to $0 \mathrm{mg}(0-0), \mathrm{p}=0.003$ and from 8.8 $\mathrm{mg}(0-25)$ to $0 \mathrm{mg}(0-0)(p=0.01)]$ in both SEA and SEA+BE, respectively. Similar results were found, comparing SEA+BE patients based on the severity of bronchiectasis.

Conclusions: Mepolizumab effectively improves asthma symptoms control, reducing annual exacerbations and corticosteroid intake in all patients with SEA, even in the subgroup with coexisting bronchiectasis, independently of their severity.

Keywords: Severe eosinophilic asthma, bronchiectasis, bronchiectasis severity index, eosinophils, neutrophils. 


\section{INTRODUCTION}

Severe refractory asthma is a heterogeneous disease with a high burden on the health care system [1-2]. Several comorbidities and risk factors [3] are frequently associated with severe asthma, identifying different phenotypes [4], and their recognition and treatment are crucial to improving asthma control and outcomes [5].

The coexistence of asthma and bronchiectasis (BE) represents an emerging phenotype [6] associated with a worse prognosis of the disease [7]. The prevalence of BE is higher in patients with severe eosinophilic asthma (SEA), ranging from 24 to $40 \%$ [5-9], and it is characterized by a late-onset disease, older age, a non-reversible airflow obstruction, rhinosinusitis, chronic mucus expectoration and frequent or severe exacerbations [10-11].

Mepolizumab, a recently released IL-5 antagonist, has shown to be an effective treatment for SEA [12], reducing exacerbations, the number of blood and sputum eosinophils, and improving pulmonary function and, therefore, asthma control [13]. Moreover, the long-term eosinophils-mediated inflammatory damage [14-15], sustained by IL-5, induces tissue changes and airway remodeling, playing a crucial role in the pathogenesis of bronchiectasis [14-16].

We hypothesized that mepolizumab would effectively improve asthma symptoms control and reduce exacerbations in a cohort of SEA with or without associated BE. We aim to evaluate the effectiveness and clinical outcomes of mepolizumab treatment in SEA patients with and without coexistence of BE and to verify its efficacy in patients with SEA+BE, according to BE severity.

\section{METHODS}

Study design and patient population 
We performed a single-center, retrospective observational study based on medical records review of patients with SEA, who were referred to the Respiratory Medicine Unit AOU "Policlinico-Vittorio Emanuele", Catania - Italy, between December 2018 and January 2020. This study adhered to the Declaration of Helsinki and received approval from the Ethics Committee "Catania 1" at Policlinico Hospital (Protocol Number 33/2020/PO).

We included all adult outpatients diagnosed with SEA according to the European Respiratory Society/American Thoracic Society (ERS/ATS) criteria [1] and Global Initiative for Asthma (GINA) 2019 report [17], requiring GINA step 4-5 treatment (high-dose inhaled corticosteroids (ICS), long-acting $\beta$-agonists (LABAs) and long-acting muscarinic receptor antagonists (LAMAs), or systemic corticosteroids $\geq 50 \%$ of the previous year to remain controlled or that remains "uncontrolled" despite this treatment) [17], prescribed with mepolizumab 100 mg subcutaneously every 4 weeks, with a continuous follow-up of at least one year.

\section{Data collection and assessment}

An established database of pertinent variables was accessed for data analysis. Socio-demographic characteristics (age, sex, BMI) and baseline asthmatic profiles information [age at onset, skin prick test to evaluate sensitization to common aeroallergen, pulmonary function test, blood eosinophils count, IgE, fractional exhaled nitric oxide (FeNO) measurement, Asthma Control Test (ACT) score [18], sputum cytology analysis, asthma exacerbation/hospitalization rate and maintenances therapies, daily corticosteroid intake (prednisone $\mathrm{mg} /$ day)], were retrieved from the database as well as the presence of comorbidities [nasal polyps, rhinosinusitis, chronic mucus hypersecretion, gastroesophageal reflux (GERD), obesity, and bronchiectasis].

All these information were collected at baseline (TO) before mepolizumab initiation, and after 6 (T6) and 12 (T12) months of biologic treatment initiation. 
Asthma exacerbations were defined as disease worsening, requiring an emergency department visit, hospitalization, and/or the use of OCS for $\geq 48 \mathrm{~h}$ or an increase of $\geq 50 \%$ in daily OCS dose [19].

Pulmonary function

Pulmonary function tests were performed according to ERS/ATS guidelines [20]. Forced Vital Capacity (FVC) and Forced Expiratory Volume in 1 second $\left(F^{2} V_{1}\right)$ were measured using a spirometer (Sensormedics, Milan, Italy). The best value of three consecutive maneuvers was expressed as the percentage of the normal. After the baseline assessment, spirometry was repeated 15 minutes after salbutamol administration (400 mcg). Reversibility of airway obstruction was expressed as a change of at least $12 \%$ of the $\mathrm{FEV}_{1}$ from baseline.

\section{Asthma Control Test}

Asthma control was assessed at baseline (T0) and after 6 (T6) and 12 (T12) months of treatment with mepolizumab using the ACT [18]. An overall score of at least 20 refers to well-controlled asthma, whereas a score $\leq 19$ reflects poor control.

\section{FeNO Measurements}

The fraction of exhaled nitric oxide was performed according to ERS/ATS guidelines [21] and was measured using the Niox ® device. FeNO levels were considered normal if FeNO was less than 25 parts per billion (ppb) and elevated if FeNO was higher than 50 ppb, as recommended [22].

\section{Induced sputum}

Sputum was induced through the inhalation of hypertonic saline solution (4.5\%) using an ultrasonic nebulizer (DeVilbiss 65; DeVilbiss Corporation, Somerset, PA, USA) [23]; sputum samples were then processed for cytological analysis. 
Gastro-esophageal reflux (GERD) diagnosis was based on patients' symptoms (heartburn and acid regurgitation) and accurate clinical history, such as extensive use of NSAIDs, as suggested by societal guidelines [24].

Chronic Rhinosinusitis with Nasal Polyps

The diagnosis of chronic rhinosinusitis with nasal polyps (CRSwNP) was formulated based on symptoms (nasal congestion, nasal discharge, facial pain/pressure, reduction/loss of smell for a minimum of 12 weeks) and objective confirmation of the presence of polyps with sinus computed tomography (CT) scan or nasal endoscopy, according to the European position paper on rhinosinusitis and nasal polyps (EPOS) 2020 [25].

Bronchiectasis diagnosis and severity

All the patients underwent high resolution computed tomography (HRCT) of the lung, as a routine exam performed in the context of severe asthma investigations in our center. The diagnosis of bronchiectasis was made based on the identification of a broncho-arterial ratio greater than 1.5 [26]. All HRCT were reported by radiologists with specific expertise in high-resolution imaging. An expert thoracic radiologist and a pulmonologist subsequently performed an independent review to confirm and score disease severity.

Bronchiectasis Severity Index (BSI) score [27] was calculated in patients affected by bronchiectasis, combining body mass index (BMI), $\mathrm{FEV}_{1} \%$ predicted, hospital admission in the past two years, number of exacerbations in the previous year, Modified Medical Research Council (MMRC) breathlessness score, radiological severity ( $\geq 3$ lobes involved or cystic changes), presence of pseudomonas and chronic bacteria colonization [28]. Microbiology testing was performed on patients' spontaneous early morning sputum samples. According to the BSI overall score (range from 0 to 26), bronchiectasis was 
defined as mild ( $\mathrm{BSI}=0-4$ points), moderate $(\mathrm{BSI}=5-8$ points), or severe (BSI $\geq 9$ points) [29].

\section{Chronic Mucus Hypersecretion}

Symptoms of chronic mucus hypersecretion $(\mathrm{CMH})$, defined as cough and sputum production on most days for at least three months a year for at least two consecutive years, were recorded [30].

Statistical analysis

Categorical variables are stated as number (n) and percentage (\%); continuous variables are expressed as mean \pm standard deviation (SD) or median and interquartile range (IQR), as appropriate. Patients were divided into two groups: SEA alone and SEA+BE, to allow for comparisons and outcomes. We further classified SEA+BE patients into two groups based on bronchiectasis severity: 1) mild BSI group and 2) moderate-tosevere BSI group.

The normality of data distribution was checked using the Shapiro-Wilk test and the Kolmogorov-Smirnov test. Fisher exact test was used for comparisons of categorical variables. Linear regression and Spearman's rank Correlation Coefficient were used to examine the relationship between variables. ANOVA for repeated measures was used for comparisons among T0 (baseline), T6 (after 6 months of mepolizumab treatment) and T12 (after 12 months of mepolizumab treatment) for continuous variables, followed by Bonferroni's correction. Friedman or Kruskal-Wallis tests were used for comparisons among T0, T6, and T12 of non-parametric variables, followed by Dunn post-hoc. In case of direct comparison between T0 and T12, paired t-test or Wilcoxon tests were used for continuous and non-normally distributed variables. Unpaired t-test or Mann-Whitney were used for comparisons between groups, as appropriate. Statistical analysis was performed using Prism version 8.2.1 (GraphPad Software Inc). A p value $<0.05$ was considered statistically significant. 


\section{RESULTS}

Patient demographics and clinical characteristics

A total of 69 patients were referred for evaluation of SEA. Thirty-two patients treated with mepolizumab and followed-up for 12 months were included in the study. The mean age of patients was $52.3 \pm 10$ years old. There was a female predominance (19/32 patients, $59 \%)$. Sixteen out of 32 patients (50\%) showed co-presence of bronchiectasis at chest HRCT and were identified as SEA+BE group. Baseline characteristics of patients and comparisons between SEA alone and SEA+BE are reported in Table 1. No statistically significant differences in terms of $\mathrm{ACT}, \mathrm{FEV}_{1} \%$, and blood eosinophil levels were noted between the groups. Annual exacerbations and daily OCS intake were more pronounced in the SEA+BE group than in SEA alone, but this difference did not reach a statistical significance. A greater proportion of patients suffered from $\mathrm{CMH}$ in the SEA+BE group than in the SEA alone [14 (87.5) vs. 5 (31.24), respectively, $p=0.0032]$. 
medRxiv preprint doi: https://doi.org/10.1101/2020.11.04.20226266; this version posted November 6, 2020. The copyright holder for this preprint (which was not certified by peer review) is the author/funder, who has granted medRxiv a license to display the preprint in perpetuity.

It is made available under a CC-BY-NC-ND 4.0 International license .

Table 1. Patients' baseline demographic and clinical characteristics.

\begin{tabular}{|c|c|c|c|c|}
\hline & $\begin{array}{l}\text { Total Population } \\
\quad(n=32)\end{array}$ & $\begin{array}{c}\text { SEA } \\
(n=16)\end{array}$ & $\begin{array}{c}\text { SEA+BE } \\
(n=16)\end{array}$ & $\mathbf{p}$ \\
\hline Age, years, mean (SD) & $52.3(10)$ & $53.2(11.9)$ & $51.3(7.9)$ & 0.60 \\
\hline Male, n (\%) & $13(40.6)$ & $5(31.3)$ & $8(50)$ & 0.47 \\
\hline BMI, mean (SD) & $26.7(5.2)$ & $28.3(5.6)$ & $25.1(4.1)$ & 0.08 \\
\hline Duration of asthma, years, mean (SD) & $19.5(12.5)$ & $17.8(12.8)$ & $21.1(12.4)$ & 0.46 \\
\hline Positive Skin Prick Test, n (\%) & $23(71.9)$ & $12(75)$ & $11(68.8)$ & $>0.99$ \\
\hline CRSwNP, n (\%) & $24(75)$ & $12(75)$ & $12(75)$ & $>0.99$ \\
\hline GERD, n (\%) & $11(34.4)$ & $8(50)$ & $3(18.8)$ & 0.13 \\
\hline Asthma exacerbations/year, median (IQR) & $7(4-12)$ & $7(4-12)$ & $8(4-12)$ & 0.88 \\
\hline ICS-LABA, n (\%) & $32(100)$ & $16(100)$ & $16(100)$ & $>0.99$ \\
\hline LAMA, n (\%) & $20(62.5)$ & $9(56.3)$ & $11(68.8)$ & 0.71 \\
\hline Patients with $\mathrm{CMH}, \mathrm{n}$ (\%) & $19(59.37)$ & $5(31.25)$ & $14(87.5)$ & $<0.01$ \\
\hline Patients on OCS, n, (\%) & $21(65.6)$ & $11(68.8)$ & $10(62.5)$ & $>0.99$ \\
\hline OCS, mg/die, median (IQR) & $8.8(0-25)$ & $8.8(0-25)$ & $15(0-25)$ & 0.68 \\
\hline ACT, mean (SD) & $13.4(4.7)$ & $13.8(4.6)$ & $13(4.8)$ & 0.63 \\
\hline $\mathrm{FEV}_{1}, \%$, mean (SD) & $75.1(22.6)$ & $76.6(20.9)$ & $73.7(24.8)$ & 0.72 \\
\hline 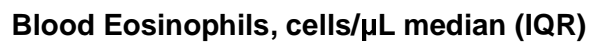 & $795(427-1308)$ & $748(400-1250)$ & $691(405-798)$ & 0.46 \\
\hline IgE, Ul/ml, median (IQR) & $213(92-414)$ & $260(92-505)$ & $177(95-329)$ & 0.31 \\
\hline FeNO, ppb, mean (SD) & $49.1(42.8)$ & $49.8(39.4)$ & $48.3(47.2)$ & 0.78 \\
\hline Sputum eosinophils, \%, median (IQR) & $22.5(16.3-49)$ & $20.5(17.3-42.3)$ & $26.5(10.8-62.8)$ & 0.90 \\
\hline Sputum neutrophils, \%, median (IQR) & $17(8.00-27.8)$ & $14.5(7-20.8)$ & $24.5(8.25-48.3)$ & 0.06 \\
\hline
\end{tabular}

Abbreviations: SEA, Severe Eosinophilic Asthma; BE, Bronchiectasis; BMI, body mass index; CRSwNP, Chronic Rhinosinusitis with Nasal Polyps; GERD, Gastroesophageal reflux disease; ICS-LABA, Inhaled Corticosteroids - Long-Acting Beta-Agonist; LAMA, Long-Acting Muscarinic Antagonist; CMH, Chronic Mucus Hypersecretion; OCS, oral corticosteroids (Prednisone); ACT, Asthma Control Test; FEV ${ }_{1}$, Forced expiratory volume in the 1st second; IgE, Immunoglobulin-E; FeNO, Fractional Exhaled Nitric Oxide; SD, standard deviation; IQR, interquartile range; ppb, parts per billion.

Indices of Mepolizumab effectiveness

Changes in indices of mepolizumab effectiveness are shown in Figure 1. The ACT score significantly improved from baseline, already after six months of mepolizumab 
treatment (T6) in both SEA $(13.8 \pm 4.6$ to $20.7 \pm 4.1, p=0.0009)$ and SEA+BE $(13 \pm 4.8$ to 20.7 $\pm 4.6, p=0.0003$ ) group, respectively. This trend of ACT score improvement was maintained during the entire study follow up, at T12, reaching a mean ACT score value of $21.9 \pm 3.1(p<0.0001)$ in the SAE alone group, Figure 1 panel A. Asthma exacerbations/year significantly lowered overall, going from 8 (4-12) to 0 (0-1) in SEA+BE and from $7(4-12)$ to $0(0.00-0.75)$ in SEA group, respectively $(\mathrm{p}<0.0001)$, Figure 1 panel B. Daily OCS dose significantly decreased at T12, changing by a median of $15 \mathrm{mg}(0-25)$ to $0 \mathrm{mg}(0-0)$ in SEA+BE group $(\mathrm{p}=0.003)$ and from $8.8 \mathrm{mg}(0-25)$ to $0 \mathrm{mg}(0-0)$ in SEA alone group $(p=0.01)$, as shown in Figure 1 panel C. A significant change in mean predicted $\mathrm{FEV}_{1}$ was observed only in the SEA+BE group, from $73.7 \% \pm 24.8 \%$ at $\mathrm{TO}$ to $85.9 \% \pm 18.3 \%$ at T6 $(p=0.02)$, as shown in Figure 1 panel D. No differences in FeNO values after treatment were noted in both groups. Chronic Mucus Hypersecretion significantly decreased in the SEA+BE group after treatment $(p=0.0011)$, as shown in Figure 1panel E. Blood eosinophils count was significantly reduced from baseline to T6 [a median of 748 cells $/ \mu \mathrm{L}(400-1250)$ vs. 84 cells $/ \mu \mathrm{L}(52.5-100),(p<0.0001)]$ in SEA and

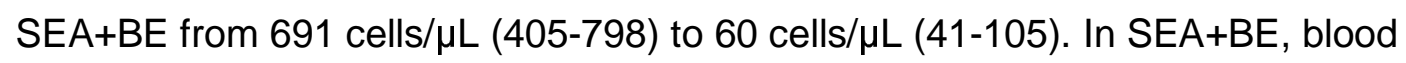
eosinophils further decreased to 49 cells/ $\mu \mathrm{L}(32.5-90),(p<0.0001)$, with a statistically significant difference in comparison to SEA at T12 $(p=0.04)$, Figure 1 panel F. Sputum eosinophil count reduced from $26.5 \%(10.8-62.8)$ to $12.5 \%(5-23)(p<0.0001)$ in SEA+BE group and from $20.5 \%(17.3-42.3)$ to $9 \%(7-10)$ at $(p<0.0001)$ in SEA group, Figure 2 panel A. Sputum neutrophils decreased from $24.5 \%(8.3-48.3)$ to $14.50 \%(4-29.8)$ in SEA+BE group ( $p=0.012)$, Figure 2 panel $B$. Indices of mepolizumab effectiveness are reported in Table 2. 


\begin{tabular}{|r|r|r|r|}
\hline & T0 & T6 & T12 \\
\hline
\end{tabular}

(A)

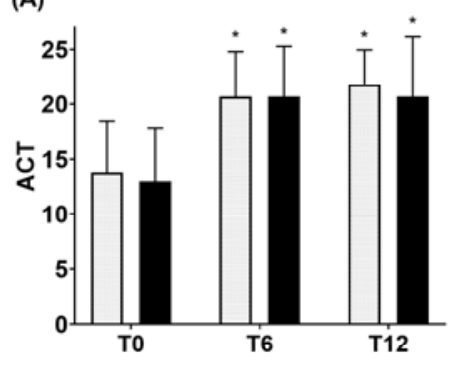

(D)

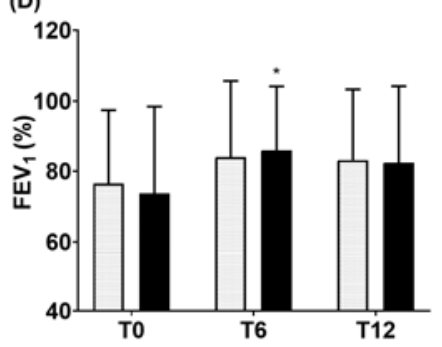

(B)

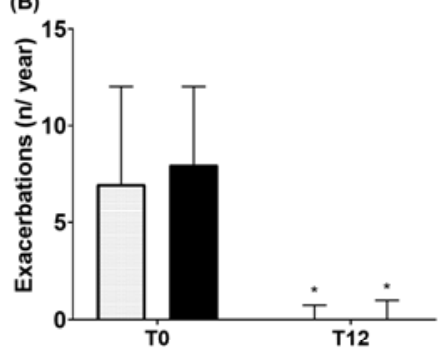

(E)

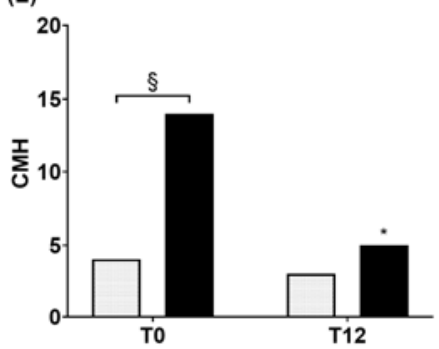

(C)

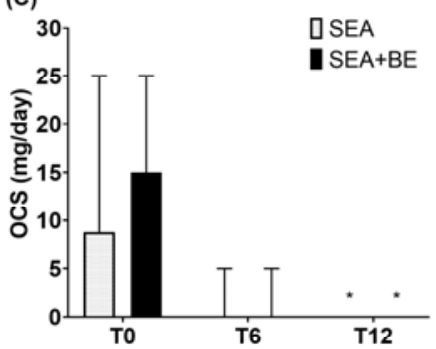

(F)

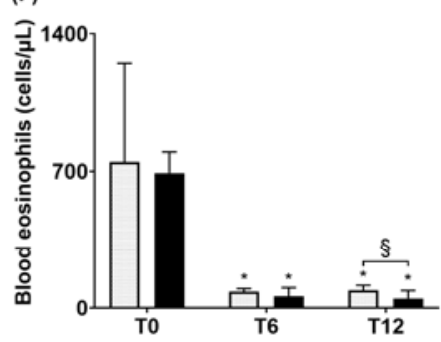

Figure 1. Effects of mepolizumab on SEA and SEA+BE groups, on ACT score (panel A),

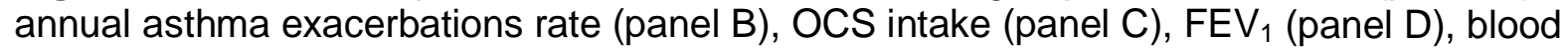
eosinophils (panel F). ACT score and $\mathrm{FEV}_{1}$ values are expressed as mean (SD). All other parameters are expressed as median values (IQR).

${ }^{*} \mathrm{p}<0.05$ T0 vs. T6/T12, $\S \mathrm{p}<0.05$ SEA vs. SEA+BE.

Abbreviations: SEA, Severe Eosinophilic Asthma; BE, Bronchiectasis; ACT, Asthma Control Test; OCS, oral corticosteroids (Prednisone); FEV ${ }_{1}$, Forced expiratory volume in the 1st second; $\mathrm{CMH}$, Chronic Mucus Hypersecretion.

(A)

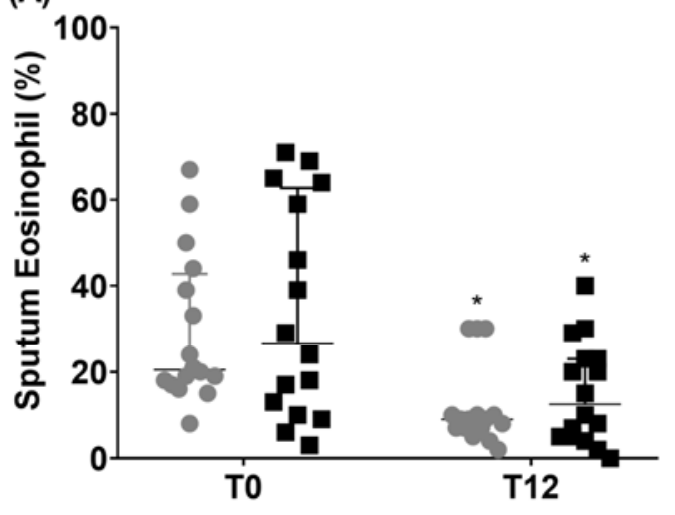

(B)

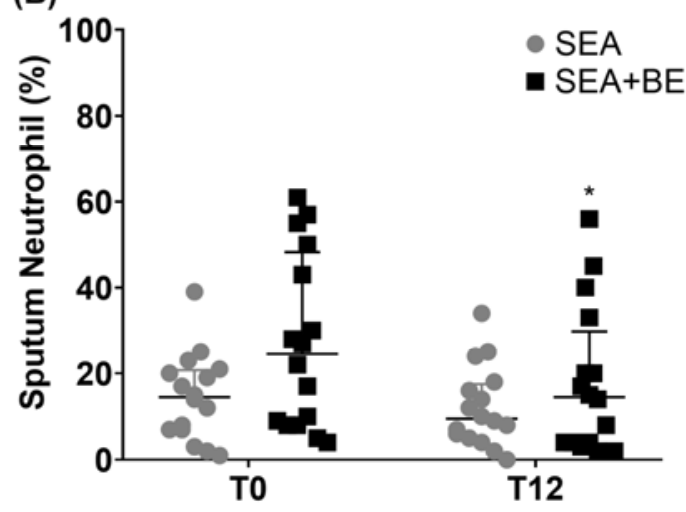

Figure 2. Effects of mepolizumab on sputum eosinophils percentage (\%), panel A and sputum neutrophil percentage (\%), panel B.

${ }^{*} \mathrm{p}<0.05$ T0 vs. T12

Abbreviations: SEA, Severe Eosinophilic Asthma; BE, Bronchiectasis; T0, baseline; T12, follow-up at 12 months. 
medRxiv preprint doi: https://doi.org/10.1101/2020.11.04.20226266; this version posted November 6, 2020. The copyright holder for this preprint (which was not certified by peer review) is the author/funder, who has granted medRxiv a license to display the preprint in perpetuity.

It is made available under a CC-BY-NC-ND 4.0 International license.

\begin{tabular}{|c|c|c|c|c|c|c|c|c|c|}
\hline & SEA & SEA+BE & $\mathbf{p}$ & SEA & SEA+BE & $\mathbf{p}$ & SEA & SEA+BE & $\mathbf{p}$ \\
\hline ACT, mean (SD) & $13.8(4.7)$ & $13(4.8)$ & 0.63 & $20.7(4.1)^{*}$ & $20.7(4.6) *$ & 0.89 & $21.8(3.1)^{*}$ & $20.7(5.5)$ * & 0.67 \\
\hline $\begin{array}{l}\text { Asthma exacerbations/year, median } \\
\text { (IQR) }\end{array}$ & $7(4-12)$ & $8(4-12)$ & 0.88 & --- & ---- & & $0(0-0.8)$ * & $0(0-1)^{*}$ & 0.75 \\
\hline OCS, mg/die, median (IQR) & $8.8(0-25)$ & $15(0-25)$ & 0.68 & $0(0-5)$ & $0(0-5)$ & 0.99 & $0(0-0)^{*}$ & $0(0-0)^{*}$ & 0.99 \\
\hline $\mathrm{FEV}_{1}, \%$, mean (SD) & $76.6(20.9)$ & $73.7(24.8)$ & 0.72 & $83.9(21.8)$ & $85.9(18.3)^{*}$ & 0.72 & $83.1(20.2)$ & $82.4(21.8)$ & 0.87 \\
\hline CMH, n (\%) & $5(31.25)$ & $14(87.5)$ & $<0.01$ & --- & -.- & & $3(18.75)$ & $4(25.0)^{*}$ & 0.68 \\
\hline 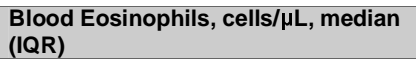 & $748(400-1250)$ & $691(405-798)$ & 0.46 & $84(52.5-100)$ * & $60(41-105)$ * & 0.32 & $90(60-117)$ * & $49(32.5-90)$ * & 0.04 \\
\hline FeNO, ppb, mean (SD) & $49.9( \pm 39.4)$ & $48.3(47.2)$ & 0.78 & $60.1(46.5)$ & $59.8(51.7)$ & 0.80 & $42.9(23.3)$ & $60.2(47.7)$ & 0.10 \\
\hline $\begin{array}{l}\text { Sputum eosinophils, \%, median } \\
\text { (IQR) }\end{array}$ & $20.5(17.3-42.3)$ & $26.5(10.8-62.8)$ & 0.90 & --- & --- & & $9(7-10)^{*}$ & $12.5(5-23)$ * & 0.41 \\
\hline Sputum neutrophils, \%, median (IQR) & $14.5(7-20.8)$ & $24.5(8.3-48.3)$ & 0.06 & -.- & 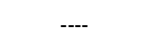 & & $9.5(5.3-17.5)$ & $14.5(4-29.8)$ * & 0.33 \\
\hline
\end{tabular}

Table 2. Indices of Mepolizumab effectiveness in severe asthma with (SEA+BE) or without Bronchiectasis (SEA).

* $\mathrm{p}<0.05$ T0 vs. T6/T12

Abbreviations: SEA, Severe Eosinophilic Asthma; BE, Bronchiectasis; BMI, body mass index; CRSwNP, Chronic Rhinosinusitis with Nasal Polyps; GERD, Gastroesophageal reflux disease; ICS-LABA, Inhaled Corticosteroids - Long-Acting Beta-Agonist; LAMA, Long-Acting Muscarinic Antagonist; CMH, Chronic Mucus Hypersecretion; OCS, oral corticosteroids (Prednisone); ACT, Asthma Control Test; FEV 1 , Forced expiratory volume in the 1st second; IgE, Immunoglobulin-E; FeNO, Fractional Exhaled Nitric Oxide; SD, standard deviation; IQR, interquartile range; ppb, parts per billion, T0, baseline; T6, follow up at 6 months; T12, follow-up at 12 months.

Mepolizumab effectiveness according to BSI

Taking into account only patients with $\mathrm{SAE}+\mathrm{BE}$, we calculated BSI in 16 patients (mean 5.5 \pm 2.3 ). We found a significant inverse linear relationship at T0 between BSI and ACT score (Figure $3 \mathrm{~A} ; \mathrm{r}=-0.7381, \mathrm{p}=0.0016$ ) and between $\mathrm{BSI}$ and $\mathrm{FEV}_{1} \%$ (Figure 3B; $r$ $=-0.5962, p=0.0165)$, respectively. No significant correlation was found between $B S I$ and duration of asthma $(r=0.14, p=0.61)$, asthma exacerbation $(r=0.07, p=0.8)$, prednisone daily dose $(r=0.06, p=0.83)$, eosinophil count in sputum $(r=0.4, p=0.12)$, neutrophil count in sputum $(r=-0.15, p=0.6)$, peripheral blood eosinophil count $(r=0.04, p=0.9), \lg E(r=-0.43$, $\mathrm{p}=0.0958)$, and FeNO $(r=0.07, p=0.8)$. 

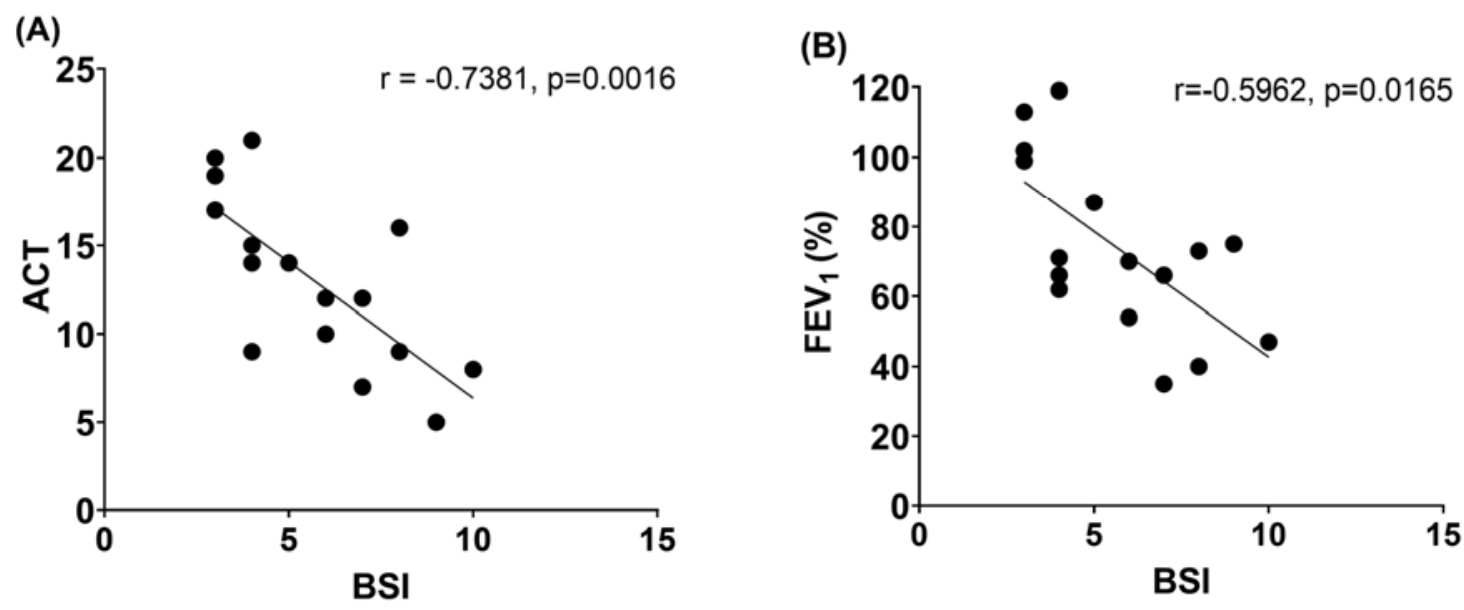

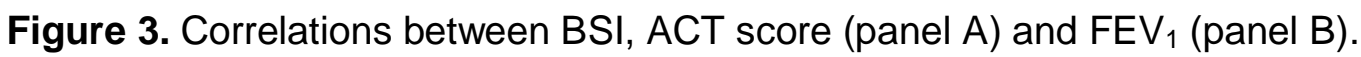
Abbreviations: BSI, Bronchiectasis Severity Index; ACT, Asthma Control Test; FEV ${ }_{1}$, Forced expiratory volume in the 1st second.

Patients were further divided according to BSI score into two groups: 1) mild BSI (0-4 points) group (7 patients, 43.7\%); and 2) moderate-to-severe BSI group [7 patients, (43.7\%) with intermediate BSI (5-8 points), and 2 patients (12.5\%) with high BSI ( $\geq 9$ points)], as shown in Table 3. 
Table 3. Baseline demographic and clinical characteristics of Mild BSI and Moderate-toSevere BSI patients.

\begin{tabular}{|c|c|c|c|}
\hline & $\begin{array}{c}\text { Mild BSI } \\
(n=7)\end{array}$ & $\begin{array}{c}\text { Moderate-to- } \\
\text { Severe BSI BSI } \\
(n=9)\end{array}$ & $\mathbf{p}$ \\
\hline Age, years, mean (SD) & $48(8.6)$ & $53.9(6.8)$ & 0.24 \\
\hline Male, n (\%) & $3(42.9)$ & $5(66.6)$ & $>0.99$ \\
\hline BMI, mean (SD) & $23.4(3.4)$ & $26.3(4.6)$ & 0.37 \\
\hline Duration of asthma, years, mean (SD) & $18.7(13.2)$ & $23(12.1)$ & 0.48 \\
\hline Positive Skin Prick Test, n (\%) & $4(57.1)$ & $7(77.7)$ & 0.59 \\
\hline CRSwNP, n (\%) & $4(57.1)$ & $8(88.8)$ & 0.26 \\
\hline GERD, n (\%) & $2(28.6)$ & $1(18.8)$ & 0.80 \\
\hline $\begin{array}{l}\text { Asthma exacerbations/year, median } \\
\text { (IQR) }\end{array}$ & $6(3-12)$ & $12(4-12)$ & 0.49 \\
\hline ICS-LABA, n (\%) & $16(100)$ & $9(100)$ & $>0.99$ \\
\hline LAMA, n (\%) & $3(42.9)$ & $8(88.8)$ & 0.10 \\
\hline Patients with $\mathrm{CMH}$, n (\%) & $6(85.7)$ & $8(88.8)$ & 0.77 \\
\hline Patients on OCS, n, (\%) & $3(42.9)$ & $7(77.7)$ & 0.49 \\
\hline OCS, mg/die, median (IQR) & $25(0-25)$ & $25(1.3-25)$ & 0.77 \\
\hline ACT, mean (SD) & $16.4(4.2)$ & $10.3(3.5)$ & $<0.01$ \\
\hline $\mathrm{FEV}_{1}, \%$, mean (SD) & $90.3(23.5)$ & $60.8(17.6)$ & $<0.01$ \\
\hline Blood eosinophil, cells/ $\mu \mathrm{L}$ median (IQR) & $718(500-800)$ & $640(370-844)$ & 0.66 \\
\hline IgE, UI/ml, median (IQR) & $216(56-431)$ & $166(102-144)$ & 0.46 \\
\hline FeNO, ppb, mean (SD) & $68.3(63.4)$ & $32.8(23.2)$ & 0.20 \\
\hline Sputum eosinophil, \%, median (IQR) & $13(9-39)$ & $46(17.5-66.5)$ & 0.20 \\
\hline Sputum neutrophil, \%, median (IQR) & $27(10-50)$ & $22(6-50)$ & 0.86 \\
\hline
\end{tabular}

Abbreviations: SEA, Severe Eosinophilic Asthma; BE, Bronchiectasis; BMI, body mass index; CRSwNP, Chronic Rhinosinusitis with Nasal Polyps; GERD, Gastroesophageal reflux disease; ICS-LABA, Inhaled Corticosteroids - Long-Acting Beta-Agonist; LAMA, Long-Acting Muscarinic Antagonist; CMH, Chronic Mucus Hypersecretion; OCS, oral corticosteroids (Prednisone); ACT, Asthma Control Test; FEV 1 , Forced expiratory volume in the 1st second; IgE, Immunoglobulin-E; FeNO, Fractional Exhaled Nitric Oxide; Severe $B S I$, moderate-to-severe BSI; SD, standard deviation; IQR, interquartile range; ppb, parts per billion.

The ACT score was significantly lower in patients with moderate-to-severe BSI compared to the mild BSI group at T0 (10.3 \pm 3.5 vs. $16.4 \pm 4.2$, respectively; $p=0.0091)$. In the mild BSI 
group, the ACT score increased from $16.4 \pm 4.2$ to $22.1 \pm 4.8$ at $\mathrm{T} 12(\mathrm{p}=0.04)$. In the moderate-to-severe BSI group, the ACT score improved significantly from $10.3 \pm 3.5$ to $21.2 \pm 4(p=0.0005)$ and 19.6 $\pm 6(p=0.003)$, at T6 and T12, respectively, as in Figure 4 panel A. Asthma exacerbations/year significantly lowered, from $6(3-12)$ to 0 (0-1) in the mild BSI $(p=0.015)$ and from $12(4-12)$ to $0(0-1)$ in the moderate-to-severe BSI group $(p=0.0078)$, as in Figure 4 panel B. Daily median OCS dose significantly decreased from 25 mg (1.3$25)$ to $0(0-0.0)$ in the moderate-to-severe BSI group $(p=0.015)$, as in Figure 4 panel $\mathrm{C}$. Mean predicted $\mathrm{FEV}_{1} \%$ was significantly lower in the moderate-to-severe BSI group compared to the mild BSI group both at T0 $(p=0.008)$ and T12 $(p=0.03)$. The $\mathrm{FEV}_{1} \%$ significantly increased in the moderate-to-severe BSI group from $60.8 \pm 17.6 \%$ to $78.2 \pm 11.2 \%$ at T6 $(p=0.01)$, as shown in Figure 4 panel D. Blood eosinophils count reduced significantly in mild BSI from a median of 718 cells $/ \mu \mathrm{L}(500-800)$ to $56 \mathrm{cells} / \mu \mathrm{L}$ (38-120) at T6 $(p=0.01)$. In patients with moderate-to-severe BSI, blood eosinophils decreased from 640 cells $/ \mu \mathrm{L}(370-844)$ to 88 cells $/ \mu \mathrm{L}(42-100)(\mathrm{p}=0.007)$ at T6 and a further reduction to 48 cells $/ \mu \mathrm{L}(35-102)(p=0.01)$ was found at T12. Sputum eosinophil count was significantly reduced to a median of $8 \%(5-23.0)(p=0.015)$ in mild BSI and $15 \%$ (4.5-24.5) $(p=0.004)$ in moderate-to-severe BSI patients, respectively as shown in Figure 5 panel A. Indices of mepolizumab effectiveness, according to BSI, are reported in Table 4. 

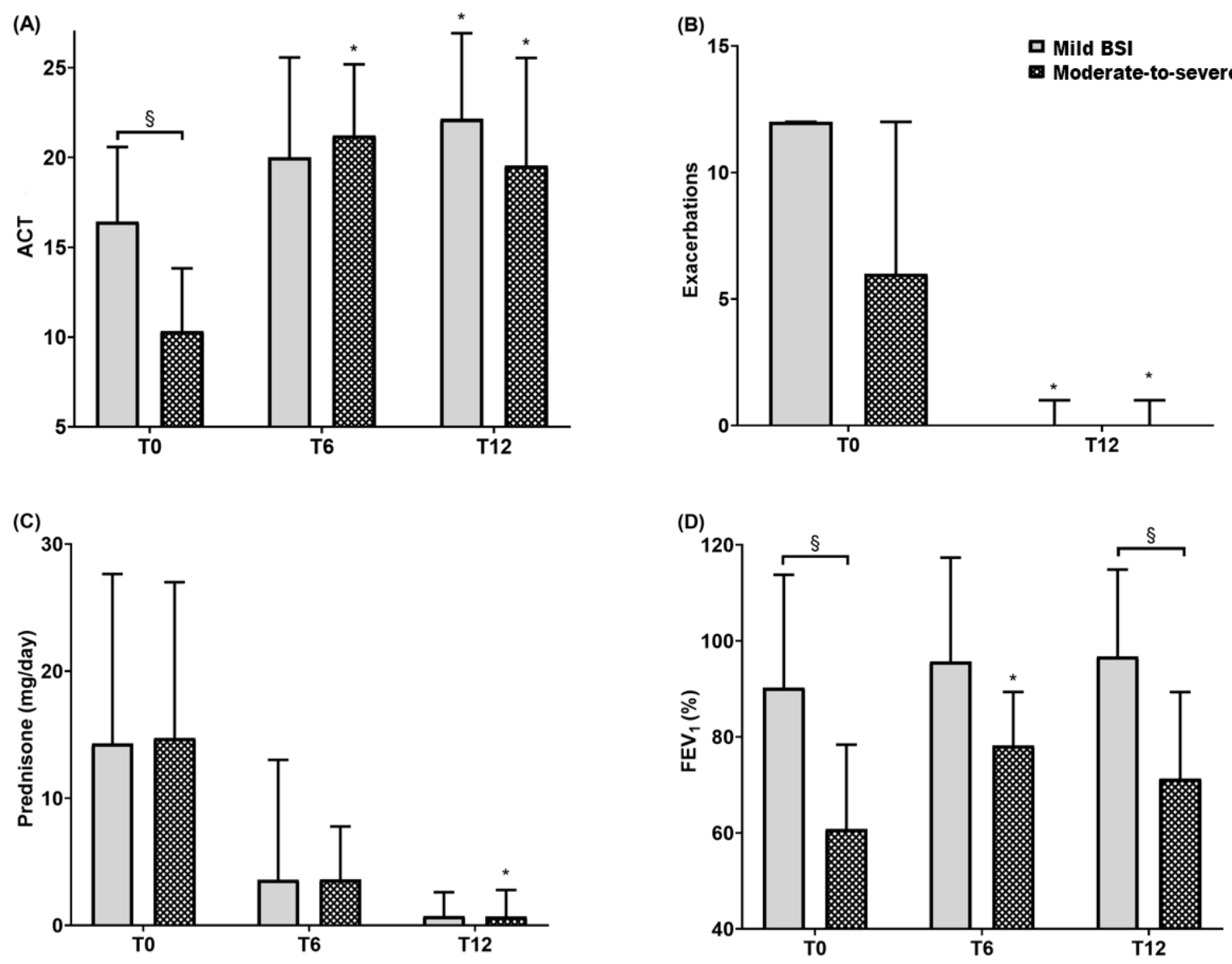

Figure 4. Effects of mepolizumab on ACT score (panel A), asthma exacerbation rate (panel B), OCS intake (panel C), $\mathrm{FEV}_{1}$ (panel D) based on the severity of bronchiectasis described as mild BSI and moderate-to-severe BSI groups. ACT score and FEV 1 values are expressed as mean (SD). All other parameters are expressed as median values (IQR). ${ }^{*} \mathrm{p}<0.05$ T0 vs. T6/T12, $\S \mathrm{p}<0.05$ Mild BSI vs. moderate-to-severe BSI Abbreviations: BSI, Bronchiectasis Severity Index; ACT, Asthma Control Test; OCS, oral corticosteroids (Prednisone); FEV 1 , Forced expiratory volume in the 1st second; SD, standard deviation; IQR, interquartile range; ppb, parts per billion, T0, baseline; T6, follow up at 6 months; T12, follow-up at 12 months. 

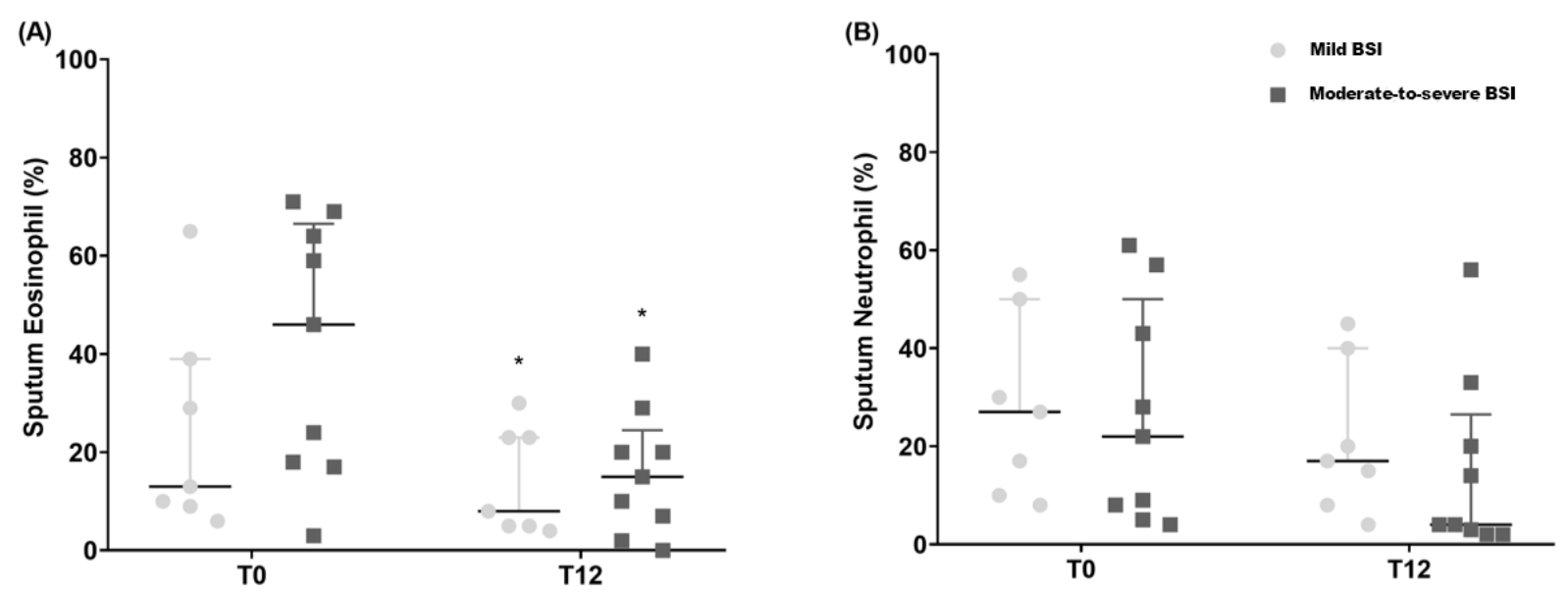

Figure 5. Mepolizumab effects on Sputum Eosinophils \% (panel A) and Sputum Neutrophil $\%$ (panel B) in Mild BSI and Mild-to-Moderate BSI.

${ }^{*} \mathrm{p}<0.05$ T0 vs. T12

Abbreviations: BSI, Bronchiectasis Severity Index; SD, standard deviation; IQR, interquartile range; ppb, parts per billion; T0, baseline; T6, follow up at 6 months; T12, follow-up at 12 months. 
medRxiv preprint doi: https://doi.org/10.1101/2020.11.04.20226266; this version posted November 6, 2020. The copyright holder for this preprint (which was not certified by peer review) is the author/funder, who has granted medRxiv a license to display the preprint in perpetuity.

It is made available under a CC-BY-NC-ND 4.0 International license .

\begin{tabular}{|c|c|c|c|c|c|c|c|c|c|}
\hline & \multicolumn{3}{|c|}{ T0 } & \multicolumn{3}{|c|}{ T6 } & \multicolumn{3}{|c|}{ T12 } \\
\hline & Mild BSI & $\begin{array}{l}\text { Moderate-to- } \\
\text { Severe BSI }\end{array}$ & p & Mild BSI & $\begin{array}{l}\text { Moderate-to- } \\
\text { Severe BSI }\end{array}$ & $p$ & Mild BSI & $\begin{array}{l}\text { Moderate-to- } \\
\text { Severe BSI }\end{array}$ & $p$ \\
\hline ACT, mean (SD) & $16.4(4.2)$ & $10.3(3.5)$ & 0.01 & $20.00(5.6)$ & $21.22(4.0)$ * & 0.89 & $22.1(4.8)$ * & $19.6(6.0)$ * & 0.57 \\
\hline $\begin{array}{l}\text { Asthma exacerbations/year, median } \\
\text { (IQR) }\end{array}$ & $6(3.0-12.0)$ & $12(4.0-12.0)$ & 0.49 & ---- & --- & & $0(0-1)^{*}$ & $0(0-1)^{*}$ & 0.99 \\
\hline Prednisone, mg/die, median (IQR) & $25(0-25)$ & $25(1.3-25)$ & 0.77 & $0(0-0)$ & $2.5(0-7.5)$ & 0.44 & $0(0-0)$ * & $0(0-0)$ * & 0.99 \\
\hline $\mathrm{FEV}_{1}, \%$, mean (SD) & $90.3(23.5)$ & $60.8(17.6)$ & 0.01 & $95.7(21.7)$ & $78.2(11.2) *$ & 0.10 & $96.7(18.2)$ & $71.3(18.0)$ & 0.03 \\
\hline CMH, n (\%) & $6(85.71)$ & $8(88.8)$ & 0.77 & ---- & --- & & $2(28.57)$ & $2(22.2)$ * & 0.99 \\
\hline $\begin{array}{l}\text { Blood Eosinophil, cells } / \mu L, \text { median } \\
\text { (IQR) }\end{array}$ & $718(500-800)$ & $640(370-844)$ & 0.66 & $56(38-120)$ * & $88(42-100)$ * & 0.32 & $60(0-90)$ * & $48(35-102)$ * & 0.59 \\
\hline FeNO, ppb, mean (SD) & $68.3(63.4)$ & $32.8(23.2)$ & 0.20 & $78.6(68.8)$ & $45.2(30.0)$ & 0.26 & $61.6(66.1)$ & $54.7(34.1)$ & 0.65 \\
\hline $\begin{array}{l}\text { Sputum eosinophils, \%, median } \\
\text { (IQR) }\end{array}$ & $13(9-39)$ & $46(17.5-66.5)$ & 0.20 & --- & --- & & $8(5-23)$ * & $15(4.5-24.5)^{*}$ & 0.27 \\
\hline $\begin{array}{l}\text { Sputum neutrophils, \%, median } \\
\text { (IQR) }\end{array}$ & $27(10-50)$ & $22(6-50)$ & 0.86 & --- & --- & & $17(8-50)$ & $4(2.5-26.5) *$ & 0.33 \\
\hline
\end{tabular}

Table 4. Indices of Mepolizumab effectiveness in severe eosinophilic asthma with associated bronchiectasis (SEA+BE) according to BSI.

${ }^{*} \mathrm{p}<0.05$ T0 vs. T6/T12

Abbreviations: SEA, Severe Eosinophilic Asthma; BE, Bronchiectasis; BMI, body mass index; CRSwNP, Chronic Rhinosinusitis with Nasal Polyps; GERD, Gastroesophageal reflux disease; ICS-LABA, Inhaled Corticosteroids - Long-Acting Beta-Agonist; LAMA, Long-Acting Muscarinic Antagonist; CMH, Chronic Mucus Hypersecretion; OCS, oral

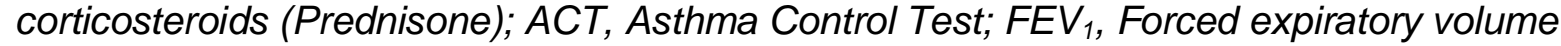
in the 1st second; IgE, Immunoglobulin-E; FeNO, Fractional Exhaled Nitric Oxide; Severe $B S I$, moderate-to-severe BSI; SD, standard deviation; IQR, interquartile range; ppb, parts per billion; T0, baseline; T6, follow up at 6 months; T12, follow-up at 12 months.

\section{DISCUSSION}

To the best of our knowledge, this is the first real-life study assessing the effectiveness of mepolizumab in patients affected by SEA and co-presence of BE in relation to their severity, according to BSI.

Overall, mepolizumab significantly improved asthma symptoms control and lung function and decreased blood eosinophils count, annual exacerbations rate, and OCS intake in the entire population of SEA patients after 6 and 12 months of treatment. These results agree with the published literature on the effectiveness of mepolizumab in this subset of patients [31, 32].

Among our population, we found a high prevalence (50\%) of BE in fulfillment with data reported in the literature [5-9]. We also found that patients with SEA+BE showed a significantly higher incidence of chronic mucus hypersecretions than patients with SEA 
alone; despite this baseline difference, mepolizumab effectively improved chronic mucus secretions in both groups. This represents a clinically significant finding since BE is a muco-obstructive disease characterized by the production of abundant, thick mucus and secretions retention that may worsen asthma symptoms' perception [33] of patients already at a very severe stage of their disease. Moreover, a clear relationship between mucus hypersecretion and high level of eosinophils in both blood [34] and bronchoalveolar lavage sample [35] has been previously reported, and it might explain our findings.

To date, the way the two diseases affect each other it is still unclear [36]. Of note, in our study, patients with SEA+BE presented a mixed inflammation, with high levels of both eosinophils and neutrophils in sputum samples at baseline that were significantly and concomitantly decreased after treatment. This result further highlights the crucial role of the eosinophilic inflammation in generating bronchiectasis. Thus, eosinophils release granule proteins such as cytotoxic proteins, peroxidases, cationic proteins, and neurotoxins $[37,38]$, determining muco-ciliary epithelium disruption and impairment of muco-ciliary clearance, mucus accumulation and distortion of bronchial architecture. This process might promote chronic bacterial colonization and subsequent neutrophilic airway inflammation [39]. Indeed, elevated eosinophils and neutrophils levels may contribute to stiffening airway mucus gel [40], forming mucus-plugs [41], further worsening airway obstruction [42] and sustaining the Cole vicious circle [40]. Moreover, stimuli such as bacterial and viral infections could cause epithelial cell death and production of IL-25, IL33, and Thymic Stromal Lymphopoietin that can stimulate Group 2 Innate Lymphoid Cells (ILC-2) proliferation [43] and further production of IL-5 [44].

Mepolizumab, preventing the interaction of IL-5 with its receptor [45], contribute to interrupting this inflammatory pathway, determining the clinical improvement we observed also in the subgroup of patients with SEA+BE. This is a clinically remarkable result since the SEA+BE phenotype is considered refractory to conventional treatment, showing a 
higher risk of exacerbations, infections, and hospitalization [46]. Our results offer speculation for a tailored treatment approach with mepolizumab of patients with $S E A+B E$, as already anecdotally reported $[8,47]$.

We found a statistically significant and clinically meaningful improvement of ACT score in SEA patients with or without co-presence of bronchiectasis, independently of their severity, despite a significantly lower pre-treatment ACT score observed in the most severe patients. From a pulmonary function standpoint, we found a significant improvement in lung function parameters overall after treatment, even in patients with associated bronchiectasis, despite their lower baseline $\mathrm{FEV}_{1} \%$. Interestingly, we observed a dramatic reduction in the annual rate of asthma exacerbations, which exceed the $50 \%$ threshold set up by the British National Institute for Health and Care Excellence (NICE) as a clinically relevant parameter to establish the efficacy of anti-asthma treatments [48]. Furthermore, we found a statistically significant reduction in patients' daily OCS dose after treatment, in line with data reported by MENSA [49] and SIRIUS [50] trials. Unsurprisingly, eosinophils were dramatically reduced after treatment in blood and sputum samples [51], confirming mepolizumab ability to dampen the cellular responses underlying type 2 asthma [52].

As expected, mepolizumab did not elicit any effects on FeNO levels [53], since NO is stimulated by different pro-inflammatory T2-cytokines, such as IL-4 and IL-13 [54-56].

To the best of our knowledge, our study is the most updated evidence of mepolizumab's effectiveness in real-world settings, taking into account also complex patients with SEA and co-presence of BE that would have been excluded by clinical trials' rigid eligibility criteria [57]. These results confirmed previous preliminary data showing the effectiveness of mepolizumab in 4 patients with SEA + BE after three months and one year of treatment [8].

\section{Strength and limitations}


The major strength of the study is the rigorous evaluation of several parameters in all our outpatients with SEA; this allowed us to register the eventual co-presence of BE and assess their severity, using the BSI and the presence of chronic mucus hypersecretion. However, our study has some limitations, mainly related to the relatively small sample size and the retrospective study design.

The limited sample size is mainly influenced by the relatively recent commercial availability and reimbursement of mepolizumab in our geographical area, at the beginning of 2018.

Given the sample size limits and the study design, our further subgroup analysis based on the BSI severity might be underpowered for adequately evaluate treatment effects across subgroups.

\section{CONCLUSIONS}

The results of this study support the hypothesis that mepolizumab elicits similar beneficial effects on $\mathrm{ACT}$ and $\mathrm{FEV}_{1} \%$ improvement and exacerbation and daily OCS reduction in patients with SEA with or without coexistence of BE and regardless of their severity. Remarkably, mepolizumab can reduce both eosinophilic and neutrophilic inflammation and chronic mucus secretions, typical SEA+BE phenotype features. This study sets the basis for future research to further support our findings and better understand the role of mepolizumab in treating severe asthma and co-presence of bronchiectasis. 


\section{References}

1. Chung KF, Wenzel SE, Brozek JL, et al. International ERS/ATS guidelines on definition, evaluation, and treatment of severe asthma [published correction appears in Eur Respir J. 2014 Apr;43(4):1216. Dosage error in article text] [published correction appears in Eur Respir J. 2018 Jul 27;52(1):]. Eur Respir J. 2014;43(2):343-373. doi:10.1183/09031936.00202013

2. Taylor DR, Bateman ED, Boulet LP, et al. A new perspective on concepts of asthma severity and control. Eur Respir J. 2008;32(3):545-554.

doi:10.1183/09031936.00155307

3. Crimi C, Campisi R, Cacopardo G, et al. Real-life effectiveness of mepolizumab in patients with severe refractory eosinophilic asthma and multiple comorbidities. World Allergy Organ J. 2020;13(9):100462. doi:10.1016/j.waojou.2020.100462

4. Kaur R, Chupp G. Phenotypes and endotypes of adult asthma: Moving toward precision medicine. J Allergy Clin Immunol. 2019;144(1):1-12. doi:10.1016/j.jaci.2019.05.031

5. Bardin PG, Rangaswamy J, Yo SW. Managing comorbid conditions in severe asthma. Med J Aust. 2018;209(S2):S11-S17.

6. Perez-Miranda J, Traversi L, Polverino E. Bronchiectasis in severe asthma: a distinct phenotype?. Curr Opin Pulm Med. 2019;25(1):71-78.

doi:10.1097/MCP.0000000000000542

7. Dimakou K, Gousiou A, Toumbis M, et al. Investigation of bronchiectasis in severe uncontrolled asthma. Clin Respir J. 2018;12(3):1212-1218.

doi:10.1111/crj.12653

8. Carpagnano GE, Scioscia G, Lacedonia D, Curradi G, Foschino Barbaro MP. Severe uncontrolled asthma with bronchiectasis: a pilot study of an emerging phenotype that responds to mepolizumab. J Asthma Allergy. 2019;12:83-90. Published 2019 Mar 5. doi:10.2147/JAA.S196200

9. Crimi C, Ferri S, Crimi N. Bronchiectasis and asthma: a dangerous liaison?. Curr Opin Allergy Clin Immunol. 2019;19(1):46-52.

doi:10.1097/ACl.0000000000000492

10. Oguzulgen IK, Kervan F, Ozis T, Turktas $\mathrm{H}$. The impact of bronchiectasis in clinical presentation of asthma. South Med J. 2007;100(5):468-471.

doi:10.1097/SMJ.0b013e31802fa16f

11. Padilla-Galo A, Olveira C, Fernández de Rota-Garcia L, et al. Factors associated with bronchiectasis in patients with uncontrolled asthma; the NOPES score: a study in 398 patients. Respir Res. 2018;19(1):43. Published 2018 Mar 16. doi:10.1186/s12931-018-0746-7

12. Busse WW. Biological treatments for severe asthma: $A$ major advance in asthma care. Allergol Int. 2019;68(2):158-166. doi:10.1016/j.alit.2019.01.004 
13. Farah CS, Badal T, Reed N, et al. Mepolizumab improves small airway function in severe eosinophilic asthma. Respir Med. 2019;148:49-53.

doi:10.1016/j.rmed.2019.01.016

14. Mao B, Yang JW, Lu HW, Xu JF. Asthma and bronchiectasis exacerbation. Eur Respir J. 2016;47(6):1680-1686. doi:10.1183/13993003.01862-2015

15. Matucci A, Vultaggio A, Maggi E, Kasujee I. Is IgE or eosinophils the key player in allergic asthma pathogenesis? Are we asking the right question?. Respir Res. 2018;19(1):113. Published 2018 Jun 8. doi:10.1186/s12931-018-0813-0

16. Schäfer J, Griese M, Chandrasekaran R, Chotirmall SH, Hartl D. Pathogenesis, imaging and clinical characteristics of CF and non-CF bronchiectasis. BMC Pulm Med. 2018;18(1):79. Published 2018 May 22. doi:10.1186/s12890-018-0630

17. Global Initiative for Asthma (GINA). GINA Report, Global Strategy for Asthma Management and Prevention, 2018 http//ginasthma.org. Accessed on March 24, 2019.

18. Nathan RA, Sorkness CA, Kosinski M, et al. Development of the asthma control test: a survey for assessing asthma control. J Allergy Clin Immunol. 2004;113(1):59-65. doi:10.1016/j.jaci.2003.09.008

19. Reddel HK, Taylor DR, Bateman ED, et al. An official American Thoracic Society/European Respiratory Society statement: asthma control and exacerbations: standardizing endpoints for clinical asthma trials and clinical practice. Am J Respir Crit Care Med. 2009;180(1):59-99. doi:10.1164/rccm.200801-060ST

20. Miller MR, Hankinson J, Brusasco V, et al. Standardisation of spirometry. Eur Respir J. 2005;26(2):319-338. doi:10.1183/09031936.05.00034805

21. American Thoracic Society; European Respiratory Society. ATS/ERS recommendations for standardized procedures for the online and offline measurement of exhaled lower respiratory nitric oxide and nasal nitric oxide, 2005. Am J Respir Crit Care Med. 2005;171(8):912-930.

doi:10.1164/rccm.200406-710ST

22. Dweik RA, Boggs PB, Erzurum SC, et al. An official ATS clinical practice guideline: interpretation of exhaled nitric oxide levels (FENO) for clinical applications. Am J Respir Crit Care Med. 2011;184(5):602-615.

doi:10.1164/rccm.9120-11ST

23. Toungoussova O, Migliori GB, Foschino Barbaro MP, et al. Changes in sputum composition during 15 min of sputum induction in healthy subjects and patients with asthma and chronic obstructive pulmonary disease. Respir Med. 2007;101(7):1543-1548. doi:10.1016/j.rmed.2006.12.009

24. Katz PO, Gerson LB, Vela MF. Guidelines for the diagnosis and management of gastro-esophageal reflux disease [published correction appears in Am J 
Gastroenterol. 2013 Oct;108(10):1672]. Am J Gastroenterol. 2013;108(3):308329. doi:10.1038/ajg.2012.444

25. Fokkens WJ, Lund VJ, Hopkins C, et al. European Position Paper on Rhinosinusitis and Nasal Polyps 2020. Rhinology. 2020;58(Suppl S29):1-464. Published 2020 Feb 20. doi:10.4193/Rhin20.600

26. Polverino E, Goeminne PC, McDonnell MJ, et al. European Respiratory Society guidelines for the management of adult bronchiectasis. Eur Respir J. 2017;50(3):1700629. Published 2017 Sep 9. doi:10.1183/13993003.00629-2017

27. Chalmers JD, Goeminne P, Aliberti S, et al. The bronchiectasis severity index. An international derivation and validation study. Am J Respir Crit Care Med. 2014;189(5):576-585. doi:10.1164/rccm.201309-1575OC

28. https://www.bronchiectasis.eu/severity-assessment

29. Costa JC, Machado JN, Ferreira C, Gama J, Rodrigues C. The Bronchiectasis Severity Index and FACED score for assessment of the severity of bronchiectasis [published online ahead of print, 2018 Jan 3]. Pulmonology. 2018;S2173-5115(17)30154-9. doi:10.1016/j.rppnen.2017.08.009

30. Fletcher CM, Pride NB. Definitions of emphysema, chronic bronchitis, asthma, and airflow obstruction: 25 years on from the Ciba symposium. Thorax. $1984 ; 39(2): 81-85$. doi:10.1136/thx.39.2.81

31. Bagnasco D, Caminati M, Menzella F, et al. One year of mepolizumab. Efficacy and safety in real-life in Italy. Pulm Pharmacol Ther. 2019;58:101836. doi:10.1016/j.pupt.2019.101836

32. Pelaia C, Busceti MT, Solinas S, Terracciano R, Pelaia G. Real-life evaluation of the clinical, functional, and hematological effects of mepolizumab in patients with severe eosinophilic asthma: Results of a single-centre observational study. Pulm Pharmacol Ther. 2018;53:1-5. doi:10.1016/j.pupt.2018.09.006

33. Dunican EM, Elicker BM, Gierada DS, et al. Mucus plugs in patients with asthma linked to eosinophilia and airflow obstruction. J Clin Invest. 2018;128(3):9971009. doi:10.1172/JCI95693

34. Siroux V, Basagaña X, Boudier A, et al. Identifying adult asthma phenotypes using a clustering approach. Eur Respir J. 2011;38(2):310-317.

doi:10.1183/09031936.00120810

35. Tanizaki Y, Kitani H, Okazaki M, et al. Nihon Kyobu Shikkan Gakkai Zasshi. 1993;31(5):575-579.

36. Dimakou K, Gousiou A, Toumbis M, et al. Investigation of bronchiectasis in severe uncontrolled asthma. Clin Respir J. 2018;12(3):1212-1218.

doi:10.1111/crj.12653 
37. Rothenberg ME, Hogan SP. The eosinophil. Annu Rev Immunol. 2006;24:147174. doi:10.1146/annurev.immunol.24.021605.090720

38. Rosenberg HF, Dyer KD, Foster PS. Eosinophils: changing perspectives in health and disease. Nat Rev Immunol. 2013;13(1):9-22. doi:10.1038/nri3341

39. Cole PJ. "Inflammation: a two-edged sword - the model of bronchiectasis". Eur J Respir Dis Suppl. 1986; 147: 6-15

40. Yuan S, Hollinger M, Lachowicz-Scroggins ME, et al. Oxidation increases mucin polymer cross-links to stiffen airway mucus gels. Sci Transl Med. 2015;7(276):276ra27. doi:10.1126/scitransImed.3010525

41. Dunican EM, Elicker BM, Gierada DS, et al. Mucus plugs in patients with asthma linked to eosinophilia and airflow obstruction. J Clin Invest. 2018;128(3):9971009. doi:10.1172/JCI95693

42. Dimakou K, Gousiou A, Toumbis M, et al. Investigation of bronchiectasis in severe uncontrolled asthma. Clin Respir J. 2018;12(3):1212-1218. doi:10.1111/crj.12653

43. Smith SG, Chen R, Kjarsgaard M, et al. Increased numbers of activated group 2 innate lymphoid cells in the airways of patients with severe asthma and persistent airway eosinophilia. J Allergy Clin Immunol. 2016;137(1):75-86.e8. doi:10.1016/j.jaci.2015.05.037

44. Yanagibashi T, Satoh M, Nagai Y, Koike M, Takatsu K. Allergic diseases: From bench to clinic - Contribution of the discovery of interleukin-5. Cytokine. 2017;98:59-70. doi:10.1016/j.cyto.2016.11.011

45. Fulkerson PC, Rothenberg ME. Targeting eosinophils in allergy, inflammation and beyond. Nat Rev Drug Discov. 2013;12(2):117-129. doi:10.1038/nrd3838

46. Polverino E, Dimakou K, Hurst J, et al. The overlap between bronchiectasis and chronic airway diseases: state of the art and future directions. Eur Respir J. 2018;52(3):1800328. Published 2018 Sep 15. doi:10.1183/13993003.003282018

47. Rademacher J, Konwert S, Fuge J, Dettmer S, Welte T, Ringshausen FC. AntiIL5 and anti-IL5Ra therapy for clinically significant bronchiectasis with eosinophilic endotype: a case series. Eur Respir J. 2020;55(1):1901333. Published 2020 Jan 23. doi:10.1183/13993003.01333-2019

48. Drick N, Seeliger B, Welte T, Fuge J, Suhling H. Anti-IL-5 therapy in patients with severe eosinophilic asthma - clinical efficacy and possible criteria for treatment response. BMC Pulm Med. 2018;18(1):119. Published 2018 Jul 18. doi:10.1186/s12890-018-0689-2

49. Ortega HG, Liu MC, Pavord ID, et al. Mepolizumab treatment in patients with severe eosinophilic asthma [published correction appears in N Engl J Med. 2015 
Apr 30;372(18):1777]. N Engl J Med. 2014;371(13):1198-1207. doi:10.1056/NEJMoa1403290

50. Bel EH, Wenzel SE, Thompson PJ, et al. Oral glucocorticoid-sparing effect of mepolizumab in eosinophilic asthma. N Engl J Med. 2014;371(13):1189-1197. doi:10.1056/NEJMoa1403291

51. Yancey SW, Keene ON, Albers FC, et al. Biomarkers for severe eosinophilic asthma. J Allergy Clin Immunol. 2017;140(6):1509-1518.

doi:10.1016/j.jaci.2017.10.005

52. Pelaia C, Crimi C, Pelaia G, et al. Real-life evaluation of mepolizumab efficacy in patients with severe eosinophilic asthma, according to atopic trait and allergic phenotype. Clin Exp Allergy. 2020;50(7):780-788. doi:10.1111/cea.13613

53. Crespo A, Giner J, Torrejón M, et al. Clinical and inflammatory features of asthma with dissociation between fractional exhaled nitric oxide and eosinophils in induced sputum. J Asthma. 2016;53(5):459-464.

doi:10.3109/02770903.2015.1116086

54. Haldar P, Brightling CE, Hargadon B, et al. Mepolizumab and exacerbations of refractory eosinophilic asthma [published correction appears in $\mathrm{N}$ Engl J Med. 2011 Feb 10;364(6):588]. N Engl J Med. 2009;360(10):973-984.

doi:10.1056/NEJMoa0808991

55. Brussino L, Heffler E, Bucca C, Nicola S, Rolla G. Eosinophils Target Therapy for Severe Asthma: Critical Points. Biomed Res Int. 2018;2018:7582057.

Published 2018 Oct 25. doi:10.1155/2018/7582057

56. Bjermer L, Alving K, Diamant Z, et al. Current evidence and future research needs for FeNO measurement in respiratory diseases. Respir Med. 2014;108(6):830-841. doi:10.1016/j.rmed.2014.02.005

57. Freemantle N, Strack T. Real-world effectiveness of new medicines should be evaluated by appropriately designed clinical trials. J Clin Epidemiol. 2010;63(10):1053-1058. doi:10.1016/j.jclinepi.2009.07.013 
medRxiv preprint doi: https://doi.org/10.1101/2020.11.04.20226266; this version posted November 6, 2020. The copyright holder for this preprint

(which was not certified by peer review) is the author/funder, who has granted medRxiv a license to display the preprint in perpetuity.

It is made available under a CC-BY-NC-ND 4.0 International license.

Acknowledgment: none.

Authors' contribution: CC conceived the content, drafted the manuscript, approved the final version to be submitted. RI, MP, GC, PI performed data collection, helped in writing the first draft, approved the final version to be submitted. RC, SN, wrote the first draft of the manuscript, performed statistical analysis and approved the final version to be submitted. CP helped in writing the manuscript, revised it critically for important intellectual content and approved the final version to be submitted. NC conceived the content, revised it critically for important intellectual content and approved the final version to be submitted.

Competing interests: All authors declare no competing interests.

Funding: This research did not receive any specific grant from funding agencies in the public, commercial, or not-for-profit sectors. 

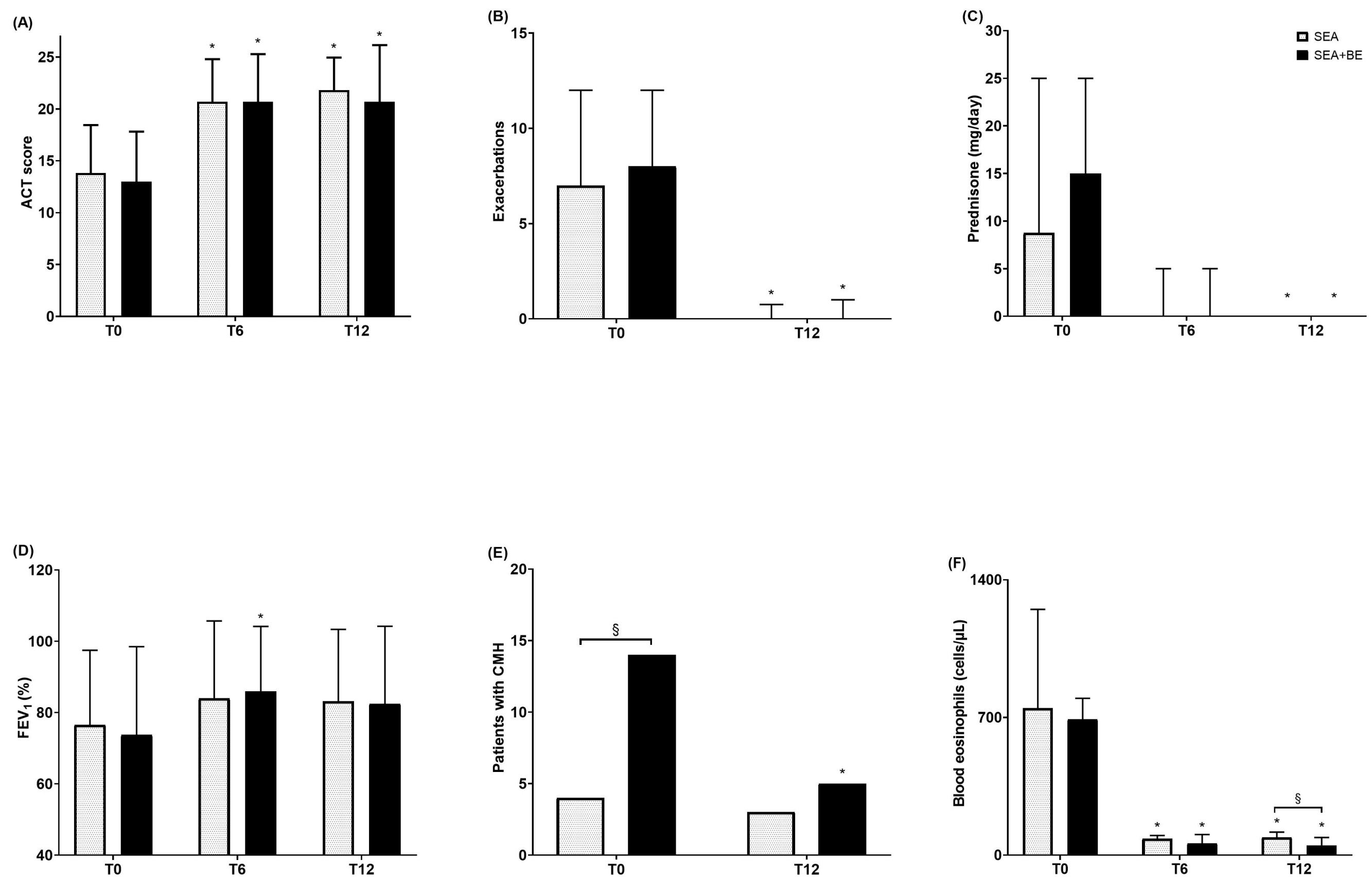


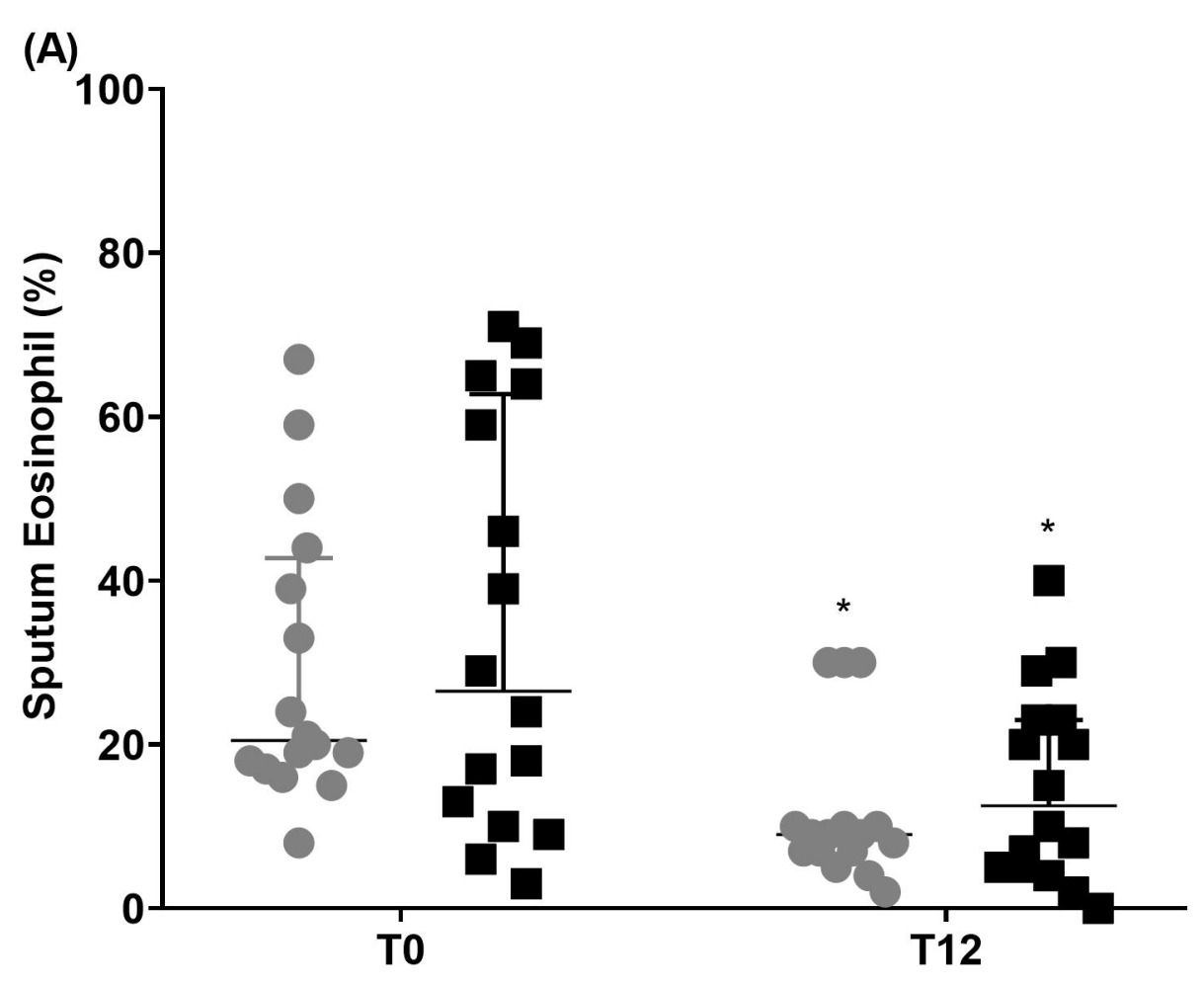

(B)

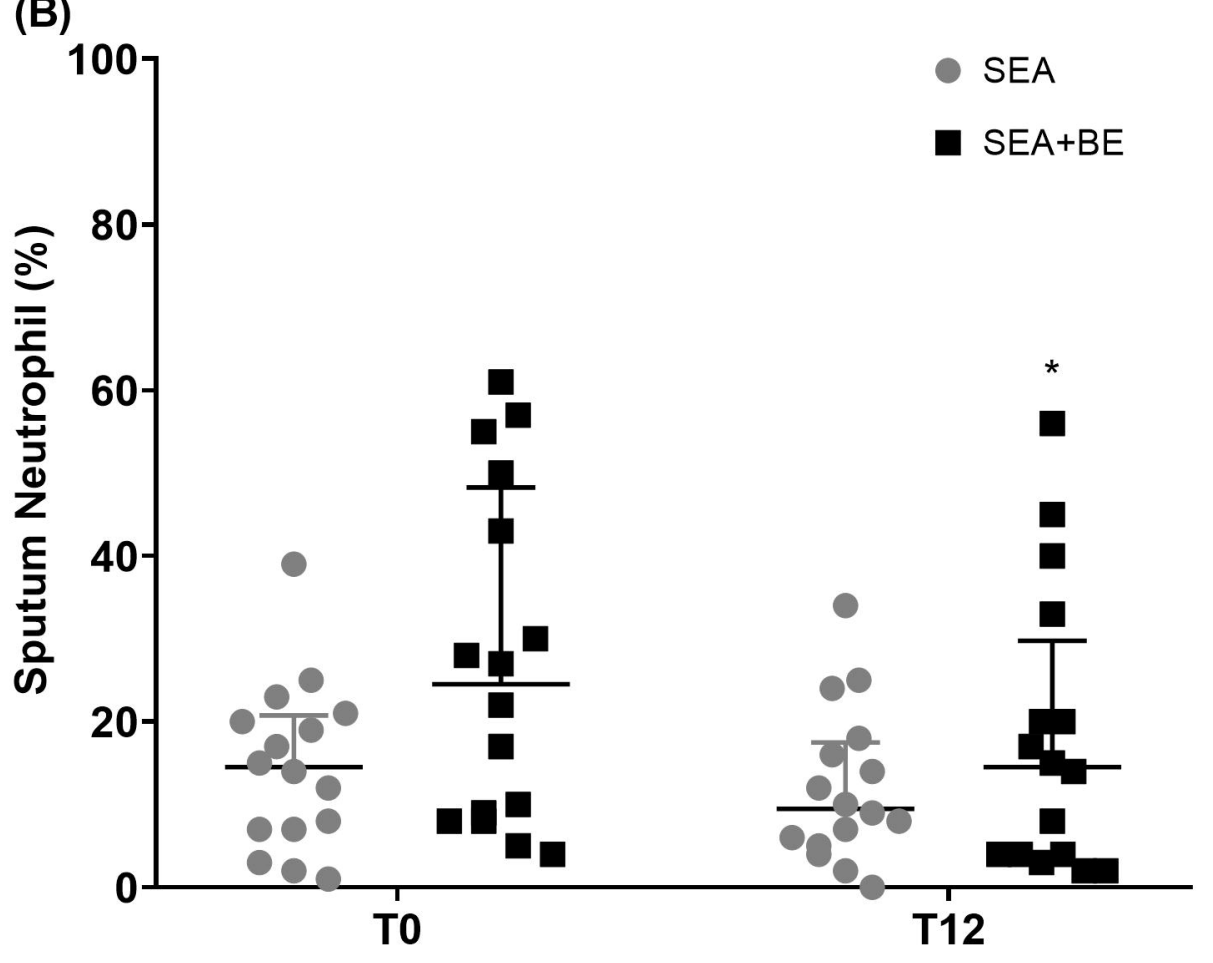



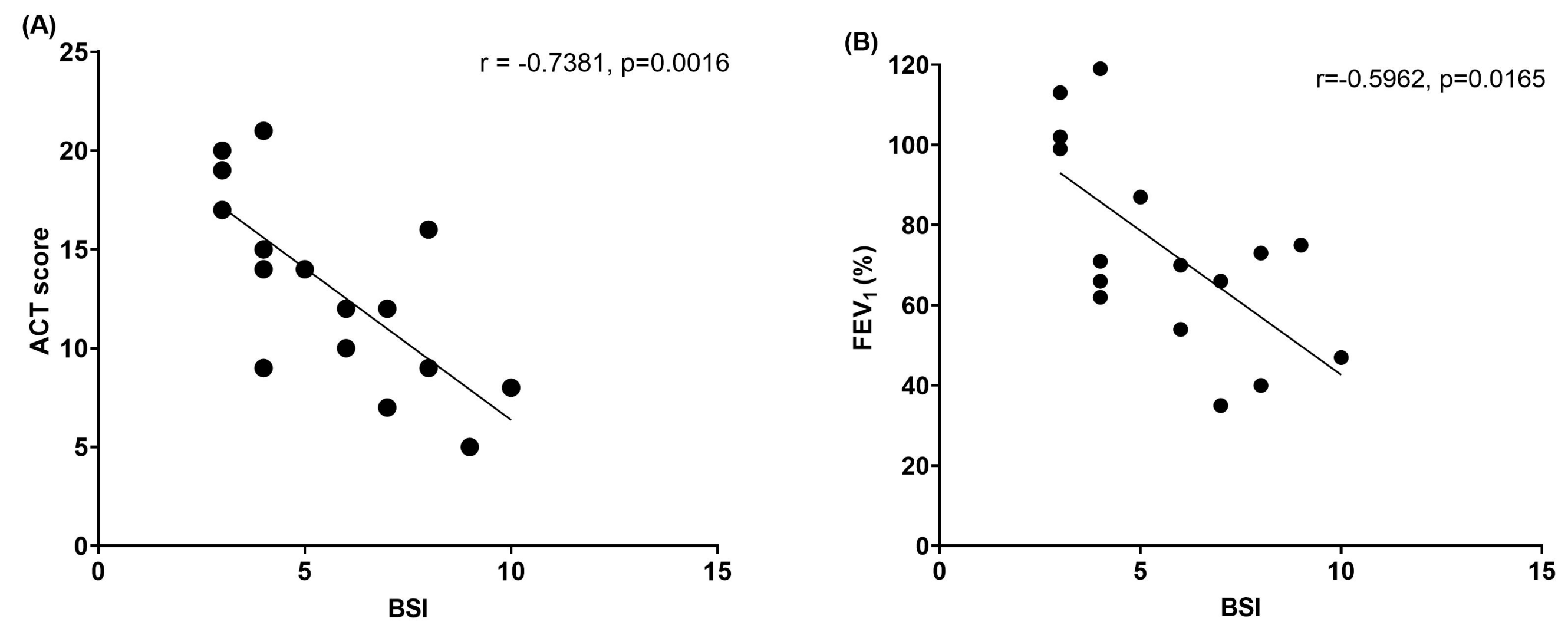

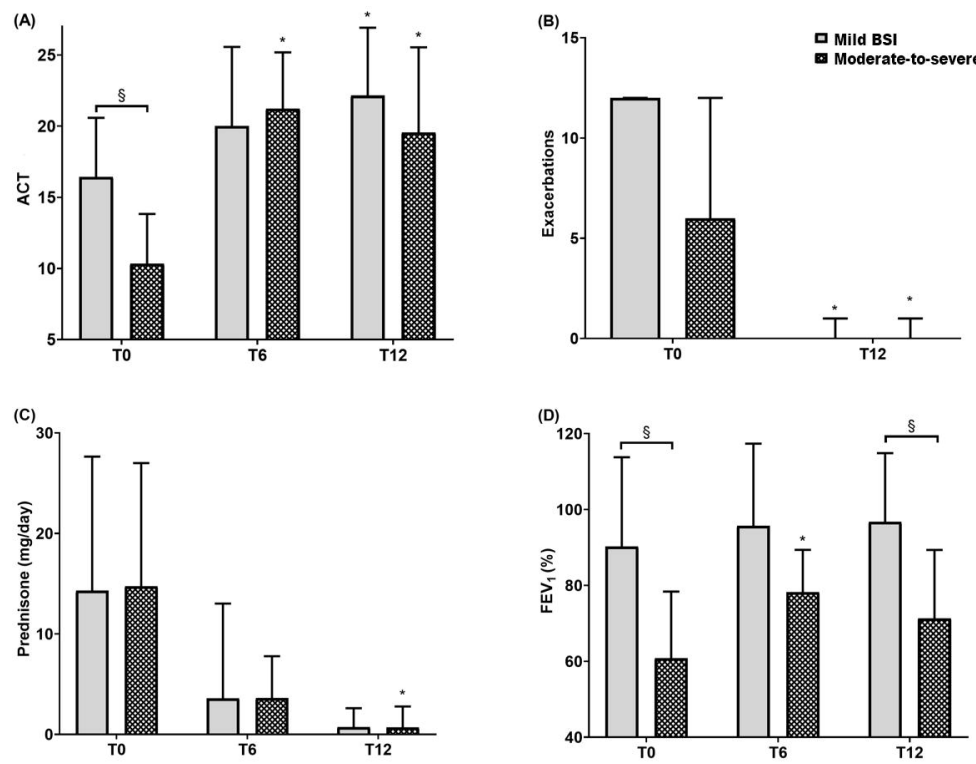

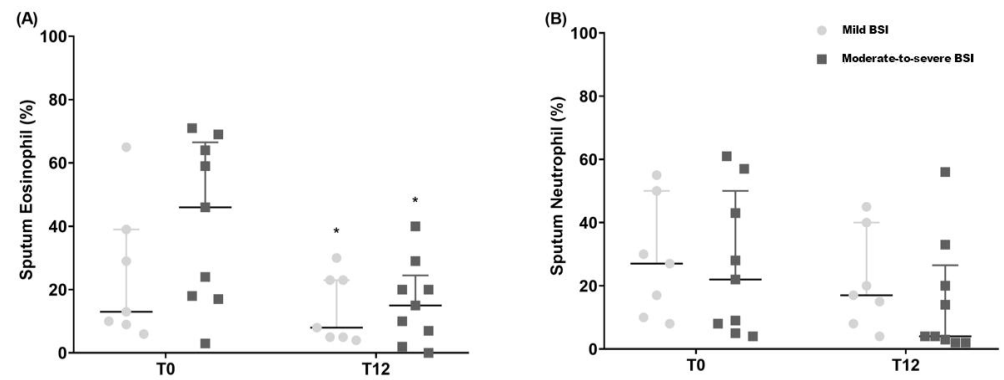